\title{
Mean Platelet Volume as an Inflammation Marker, Possible Biomarker of Tumor Detection in Prostate Biopsy
}

\author{
Caner Ediz ${ }^{1}$, Serkan Akan1, Omer Yilmaz ${ }^{1},{\text { Muhammed Cihan Temel}{ }^{1}, \text { Ozlem Koksal }}^{2}$ \\ ${ }^{1}$ Department of Urology, Sultan Abdulhamid Han Education and Research Hospital, Istanbul, Turkey \\ ${ }^{2}$ Department of Biostatistics, Sultan Abdulhamid Han Education and Research Hospital, Istanbul, Turkey \\ Email: *drcanerediz@gmail.com
}

How to cite this paper: Ediz, C., Akan, S., Yilmaz, O., Temel, M.C. and Koksal, O. (2019) Mean Platelet Volume as an Inflammation Marker, Possible Biomarker of Tumor Detection in Prostate Biopsy. Open Journal of Urology, 9, 31-41.

https://doi.org/10.4236/oju.2019.92004

Received: January 10, 2019

Accepted: February 10, 2019

Published: February 13, 2019

Copyright $\odot 2019$ by author(s) and Scientific Research Publishing Inc. This work is licensed under the Creative Commons Attribution International License (CC BY 4.0).

http://creativecommons.org/licenses/by/4.0/

\begin{abstract}
Background: In the diagnosis of prostatic diseases, the need for markers other than prostate specific antigen (PSA) has been increasing in recent years. So, we aimed to determine the predictive value, the neutrophil lymphocyte ratio, platelet-to-lymphocyte ratio and mean platelet volume before prostate biopsy in predicting the results of pathology. Transrectal ultrasound-guided biopsy of the prostate was performed because of high PSA values and compared values of these parameters to predict of pathology results. Methods: 2715 patients who underwent 10 - 12 quadrant transrectal ultrasound-guided prostate biopsies between January 2008 and January 2018 have been evaluated retrospectively. Patients were divided into groups according to the biopsy pathology results by benign (group 1), atypical small acinar proliferation (ASAP) (group 2) and prostate cancer (group 3). A total of 204 patients who were benign prostate hyperplasia in 71 patients (34.8\%), atypical small acinar proliferation in $80(39.21 \%)$ and prostate adenocarcinoma ( $\mathrm{PCa})$ in 53 patients $(25.98 \%)$ were included in the study by systematic sampling. Before the biopsy total PSA (tPSA), free PSA (fPSA), rate of percentage of free to total prostate specific antigen (f/tPSA) rate, PSA density (PSA-D), white blood cell (WBC) count, blood neutrophil count (NC), blood lymphocyte count (LC), neutrophil lymphocyte ratio (NLR), mean platelet volume (MPV), platelet count (PLT) and platelet-to-lymphocyte ratio (PLR) were measured and compared in all groups. Differences in continuous variables were assessed using the ANOVA. Logistic regression was used to analyze the linear relationship between predictive variables and pathology results. $\mathrm{P}<0.05$ was considered statistically significant. Results: NLR and PLR values were lower in group 1 than group 2 and were found statistically significant between in group 1 and group 2 (p: 0.03 and p: 0.02, respectively). MPV value was found 1.7 times higher in patients who were diagnosed with ASAP pathology than
\end{abstract}


those with benign pathologies. Although there was statistically significant increase in MPV values in logistic regression results, no statistically significant diagnostic value was found. In addition MPV value was found 0.5 times higher in patients who were diagnosed patients with ASAP than prostate cancer group. ROC analysis showed that the optimal threshold was 7.65 femtoliter (sensitivity: 51\%; specificity: $30 \%$ ) and was found to be a statistically significant diagnostic value to distinguish groups 2 and 3 . The lowest value of MPV was found in group 3. Conclusions: In cases where the PSA value is insufficient in predicting the pathology result, the effect of NLR, PLR and MPV on differential diagnosis can be kept in mind. While NLR and PLR are more useful in the diagnosis of ASAP, MPV is more effective in the diagnosis of malignancy.

\section{Keywords}

Mean Platelet Volume, Neutrophil Lymphocyte Ratio,

Platelet-to-Lymphocyte Ratio, Prostate Biopsy, Prostate Cancer, Atypical

Small Acinar Proliferation

\section{Introduction}

Prostate cancer (PCa) is the second most common cancer in men. The gold standard for diagnosis of PCa is transrectal ultrasound guided (TRUS) prostate biopsy. The Prostate-Specific Antigen (PSA) alone is not sufficient in the prediction of the outcomes of the prostate biopsy. For this reason, unnecessary biopsy can be performed in cases with elevation of the PSA such as age-related prostate enlargement or prostate inflammation. Also there is a possibility of detecting prostate cancer at each PSA level and the likelihood of a negative prostate biopsy is increased as the PSA threshold value decreases.

Complete Blood Count (CBC) and its parameters are evaluated before routine prostate biopsy. Many parameters and derivatives such as neutrophil lymphocyte ratio, platelet lymphocyte ratio, and mean platelet volume were demonstrated in the literature with positive predictive results of cancer diagnosis, tumor progression or tissue inflammation level [1] [2] [3]. However, studies on these parameters did not have high-level evidence-based results that prostate cancer guidelines could offer.

We aimed to assess the relationship between $\mathrm{CBC}$ parameters and prostate biopsy results in patients with elevation of the PSA and determine the effect of $\mathrm{CBC}$ parameters in differential diagnosis of cancer.

\section{Materials and Methods}

\subsection{Study Population}

2715 patients with prostate biopsy performed due to high PSA or significant DRE findings in Sultan Abdulhamid Han Education and Research Hospital be- 
tween January 2008 and January 2018 were enrolled retrospectively. Pathology results of 2715 patients were divided into 3 groups as benign, ASAP and malign. Patient groups were formed by systematic sampling of patients with benign and malignant pathology in prostate biopsy. Since ASAP was a very frequent pathology, there was no need for systematic sampling to select patients. A total of 204 patients who were benign prostate hyperplasia in 71 patients (34.8\%), atypical small acinar proliferation in $80(39.21 \%)$ and prostate adenocarcinoma (PCa) in 53 patients $(25.98 \%)$ were included in the study by systematic sampling.

The criteria for inclusion in the study were as follows: Digital rectal examination results suggestive or non-suggestive of neoplasia or elevated PSA $(>2.5$ $\mathrm{ng} / \mathrm{mL}$ in men) and evaluation of $\mathrm{CBC}$ results in the last week before prostate biopsy.

The criteria for exclusion in the study were as follows: Diesease of coagulopathies, patients with urinary tract infections, individuals who have had surgery in the past year, total number of cores less or more than 10 in prostate biopsy and patients with inadequate data.

\subsection{Clinical Examination and Biochemical Measurements}

Patients' age, TRUS calculated PVs with the ellipse method (length X depth X width $\mathrm{X} \pi / 6$ ), total PSA (tPSA), free PSA (fPSA), rate of percentage of free to total prostate specific antigen (f/tPSA) rate, PSA density (PSA-D) that was calculated as total PSA $(\mathrm{ng} / \mathrm{mL} / \mathrm{cc})$ divided by prostate volume $(\mathrm{cc})$, white blood cell (WBC) count, blood neutrophil count (NC), blood lymphocyte count (LC), neutrophil lymphocyte ratio (NLR), mean platelet volume (MPV), platelet (PLT) count and platelet-to-lymphocyte ratio (PLR) were evaluated before the initial biopsy in all patients.

One day before the TRUS guided prostate biopsy, oral administration of 500-mg levofloxacin was started and it was continued until the end. The day of biopsy a rectal enema $(250 \mathrm{~mL})$ was performed before the biopsy. The procedure was performed while the patient was in the left lateral position with the thighs flexed. The procedure was performed under the guidance of ultrasound device with a $7.5 \mathrm{mHz}$ biplanar probe.

The biopsy was performed on an outpatient basis in a room equipped with all material necessary for emergency intervention. Sedation and anesthesia were not achieved. 10 minutes before the procedure, periprostatic nerve block was performed in addition to perianal intrarectal lidocain gel. Injections were delivered at the angle between the seminal vesicle and prostate on each side using $5 \mathrm{cc}$ of $2 \%$ lidocain. The biopsies were performed by multiple experienced urologists. Standard 10 - 12 (both lateral and medial biopsies from the base, medial and apex on the right and left side of the prostatic peripheral zone) core biopsy was performed in prostate biopsies.

Pathological specimens were reviewed by a single genitourinary pathologist based on the 2005 and 2014 International Society of Urological Pathology (ISUP) Consensus Conference grading of prostate cancer. The patients who were diag- 
nosed with prostate cancer before 2014 were evaluated using 2005 ISUP grading criteria and patients who were followed-up after 2014 were classified using the 2014 ISUP new grading system [4] [5].

\subsection{Statistical Analysis}

In the analysis of the data, the normality hypothesis was first investigated using the kolmogorov-smirnov test. The descriptive statistics are presented as means \pm SD for continuous variables. Differences in continuous variables were assessed using the ANOVA (Post Hoc: Scheffe). Logistic regression was used to analyze the linear relationship between variables and pathology results. Correlation and effect was assessed using the Hosmer-Lemeshow goodness-of-fit test. Odds ratios (ORs) with 95\% confidence intervals (CIs) were also calculated. Receiver operating characteristic (ROC) curves were used to quantify the predictive accuracy of the logistic models. ROC curves were calculated to analyze area under the curve (AUC) values of measured serum markers and the differences in the AUC were detected. We constructed ROC curves by plotting sensitivity against 1 - specificity. Two-tailed values of $\mathrm{P}<0.05$ were considered statistically significant. Statistical analyses were performed using SPSS Statistics version 22.0 (SPSS Inc., Chicago, IL, USA).

\section{Results}

The mean ages of the patients with benign pathology, ASAP and PCa were 61.92 (7.16), 63.82 (7.64) and 68.2 (6.99) years in group 1, 2 and 3, respectively. The patients' mean age, prostate volumes, tPSA, fPSA, f/tPSA, PSA-D, WBC count, NC, LC, NLR, MPV, PLT count and PLR were shown in Table 1.

Table 1. Demographic characteristics and laboratory tests results in all groups. Data are presented as mean \pm standard deviation.

\begin{tabular}{cccc}
\hline Variables & $\begin{array}{c}\text { Group 1 } \\
\text { Mean } \pm \text { SD }\end{array}$ & $\begin{array}{c}\text { Group 2 } \\
\text { Mean } \pm \text { SD }\end{array}$ & $\begin{array}{c}\text { Group 3 } \\
\text { Mean } \pm \text { SD }\end{array}$ \\
\hline Patients $(\mathrm{n})$ & 71 & 80 & 53 \\
\hline Age $($ years $)$ & $61.92 \pm 7.16$ & $63.82 \pm 7.64$ & $68.2 \pm 6.99$ \\
PV $(\mathrm{ml})$ & $50.73 \pm 22.07$ & $54.24 \pm 28.67$ & $41.15 \pm 18.55$ \\
tPSA $(\mathrm{ng} / \mathrm{mL})$ & $6.96 \pm 4.85$ & $8.52 \pm 6.14$ & $18.39 \pm 26.05$ \\
fPSA $(\mathrm{ng} / \mathrm{mL})$ & $1.79 \pm 2.26$ & $1.73 \pm 1.5$ & $3.78 \pm 7.36$ \\
f/tPSA & $23.79 \pm 12.6$ & $20.64 \pm 8.58$ & $17.36 \pm 7.45$ \\
PSA-D $\left(\mathrm{ng} / \mathrm{mL}^{2} \mathrm{cc}\right)$ & $0.14 \pm 0.08$ & $0.19 \pm 0.2$ & $0.47 \pm 0.63$ \\
WBC Count $\left(10^{3} / \mathrm{mm}^{3}\right)$ & $7.55 \pm 1.77$ & $7.92 \pm 2.63$ & $7.55 \pm 2.67$ \\
NC $\left(10^{3} / \mathrm{mm}^{3}\right)$ & $4.53 \pm 1.23$ & $5.07 \pm 2.42$ & $4.63 \pm 2.39$ \\
LC $\left(10^{3} / \mathrm{mm}^{3}\right)$ & $2.38 \pm 1.01$ & $2.26 \pm 1.09$ & $2.26 \pm 0.69$ \\
$\mathrm{NLR}$ & $2.06 \pm 0.7$ & $2.85 \pm 2.64$ & $2.15 \pm 1$ \\
MPV $(\mathrm{fL})$ & $7.91 \pm 1.04$ & $8.29 \pm 1.37$ & $7.74 \pm 1.15$ \\
PLT Count $\left(10^{3} / \mathrm{mm}^{3}\right)$ & $224.15 \pm 52.82$ & $247.1 \pm 91.73$ & $224.38 \pm 70.76$ \\
PLR $(\%)$ & $102.55 \pm 34.87$ & $125.88 \pm 65.64$ & $105.84 \pm 40.03$ \\
\hline
\end{tabular}


The mean prostate volumes, tPSA, fPSA, f/tPSA, PSA-D, WBC count, NC, LC, NLR, MPV, PLT count and PLR statistical analysis results in comparison of groups as Group 1-2 (G1-2), Group 2-3 (G2-3) and Group 1-3 (G1-3) were shown in Table 2.

tPSA, fPSA, f/tPSA ratio and PSA-D values were found statistically significant between in group 1 and group 3 (p: 0.001, p: 0.03, p: 0.001 and p: 0.001, respectively).PV, tPSA, fPSA, PSA-D and MPV were found statistically significant between in group 2 and group 3 (p: 0.01, p: 0.001, p: 0.02, p: 0.001 and p: 0.04, respectively).

CBC parameters were not found to be statistically significant in the differential diagnosis of group 1 and 3 as a predictor of pathology result $(p>0.05)$. NLR and PLR were lower in group $1(2.06 \pm 0.7$ and $102.55 \pm 34.87)$ than group 2 $(2.85 \pm 2.64$ and $125.88 \pm 65.64)$ were found statistically significant between in group 1 and 2 (p: 0.03 and p: 0.02, respectively).

Compared with group 1, group 2 had significantly higher odds of MPV and PLT counts. (OR: 1.73, 95\% CI: 1.19 - 2.51 p: 0.003 and OR: 1.01, 95\% CI: 1 1.03, p: 0.035 , respectively). Hosmer and Lemeshow goodness-of-fit tests indicated that model was a good fit $(\mathrm{p}=0.46)$. ROC curves of MPV and PLT count were constructed to assign optimal cutoff values associated with ASAP. Although there was a statistically significant increase in MPV and PLT counts in logistic regression results, no statistically significant cut-off value was found (Figure 1). Compared with group 3, group 2 had significantly higher odds of MPV (OR: 0.56, 95\% CI: 0.39 - 0.81 p: 0.002). Hosmer and Lemeshow goodness-of-fit tests indicated that model was a good fit $(\mathrm{p}=0.67)$. ROC curve of MPV was constructed to assign optimal cutoff values associated with malignity. The analysis showed that baseline MPV higher than $7.65 \mathrm{fL}$ indicates the presence of malignity with $51 \%$ sensitivity and $30 \%$ specificity (Figure 2 ).

Table 2. P-values determined by statistical analysis between all groups.

\begin{tabular}{|c|c|c|c|}
\hline \multicolumn{4}{|c|}{ P-value } \\
\hline Variable & G1-G2 & G2-G3 & G1-G3 \\
\hline $\mathrm{PV}(\mathrm{ml})$ & 0.67 & $0.01^{*}$ & 0.09 \\
\hline tPSA (ng/mL) & 0.80 & $0.001^{\star}$ & $0.001^{\star}$ \\
\hline fPSA (ng/mL) & 1 & $0.02^{*}$ & $0.03^{*}$ \\
\hline f/tPSA (\%) & 0.15 & 0.18 & $0.001^{\star}$ \\
\hline PSA-D (ng/mL/cc) & 0.65 & $0.001^{*}$ & $0.001^{\star}$ \\
\hline WBC Count $\left(10^{3} / \mathrm{mm}^{3}\right)$ & 0.63 & 0.68 & 1 \\
\hline $\mathrm{NC}\left(10^{3} / \mathrm{mm}^{3}\right)$ & 0.28 & 0.49 & 0.96 \\
\hline $\mathrm{LC}\left(10^{3} / \mathrm{mm}^{3}\right)$ & 0.77 & 1 & 0.80 \\
\hline NLR (\%) & $0.03^{*}$ & 0.09 & 0.97 \\
\hline MPV (fL) & 0.17 & $0.04^{*}$ & 0.73 \\
\hline PLT Count $\left(10^{3} / \mathrm{mm}^{3}\right)$ & 0.17 & 0.23 & 1 \\
\hline PLR (\%) & $0.02^{*}$ & 0.08 & 0.94 \\
\hline
\end{tabular}

*: p < 0.05, G 1, 2, 3: Group 1, 2, 3. 


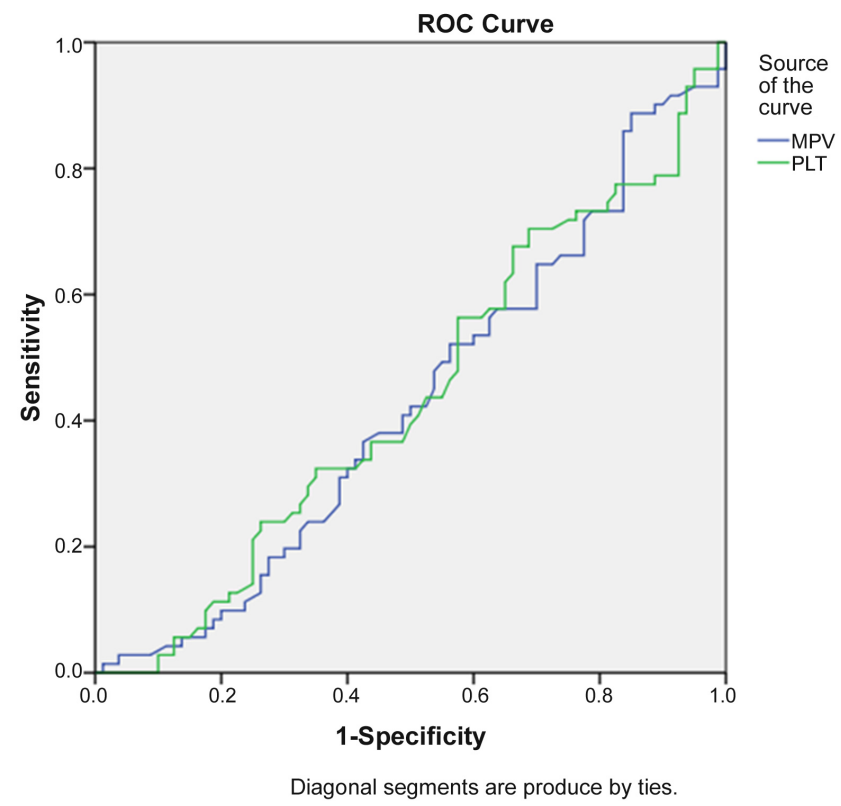

Figure 1. Receiver operating characteristic curves for MPV and PLT count to predict ASAP. Cutoff value was not found for MPV and PLT count.

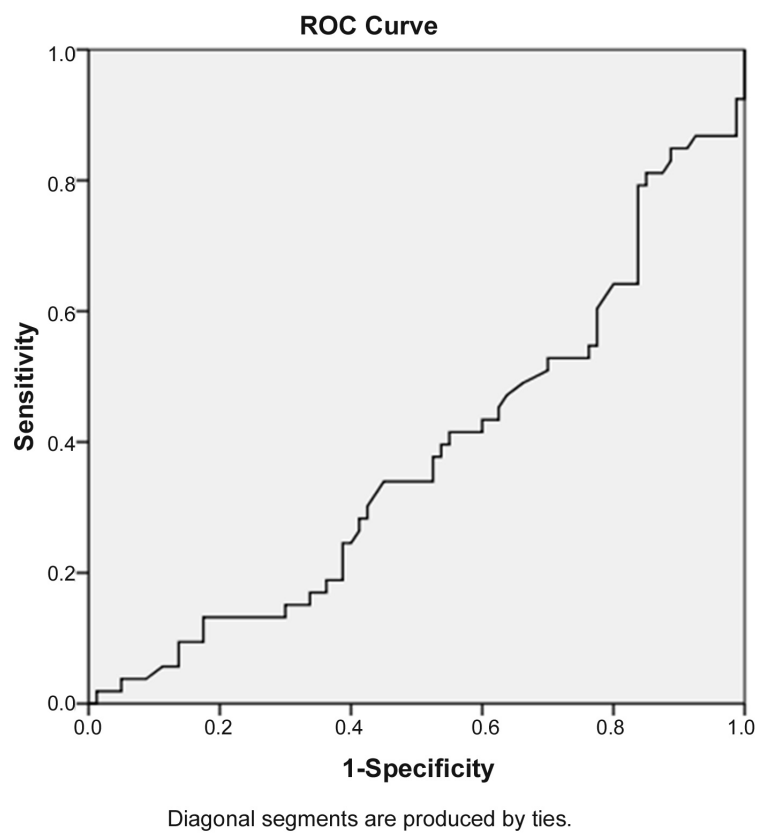

Figure 2. Receiver operating characteristic curve for MPV topredict prostate cancer. Cutoff value $=7.65 \mathrm{fL}$; sensitivity $=50.9 \%$; specificity $=30 \%$; $\mathrm{AUC}=0.378$.

\section{Discussion}

Prostate cancer is the most common cancer in men [6]. Transrectal ultrasound (TRUS) guided prostate biopsy is the gold standard for the diagnosis of prostate cancer [7]. The sensitivity of TRUS guided prostate biopsy for the diagnosis of prostate cancer ranges between $49 \%$ and $87 \%$, and specificity ranges between $38 \%$ and $93 \%$ [8] [9]. Several factors may influence the accuracy of biopsy results 
such as practitioner experience, insufficient tissue sampling and side effects as infection or erectile dysfunction. Multi-parametric magnetic resonance imaging (mpMRI) scan may increase this accuracy rate. However, it is not possible to apply it to every patient because of its high cost. The need for a cost-effective and easily accessible test that can positively affect the prediction of the prostate biopsy results is very obvious.CBC parameters such as WBC count, NC, LC, NLR, MPV, PLT count and PLR routinely evaluated before prostate biopsy can meet this requirement.

Age-adjusted incidence of PCa starts in the 50s and peaks in the 70s [10]. In our cohort, patients with benign pathology were found to be at an earlier age in accordance with the literature, and ASAP and malignant pathology results were more common in the later ages together with increasing cellular mutation.

The predictive value of tPSA in the differential diagnosis between benign pathology and ASAP is poor [11]. Ouyang, et al. [12] did not found to demonstrate a direct relationship between ASAP and PSA. In our study, tPSA levels were higher in patients with ASAP than benign pathologies but not statistically significant. Although tPSA, fPSA, f/tPSA ratio and PSA-D did not differ between group 1 and 2 in our cohort, they were significant predictor of positive re-biopsy result in patients with ASAP [13] [14].

tPSA, fPSA, f/tPSA ratio and PSA-D are effective and reliable for distinction of benign tissue and malignant prostate tissue [15] [16] [17]. In our cohort, tPSA, fPSA, f/tPSA ratio and PSA-D were found statistically significant between in group 1 and group 3 consistent with the literature (p: $0.001^{*}, \mathrm{p}: 0.03, \mathrm{p}$ : $0.001^{\star}, \mathrm{p}: 0.001$, respectively). tPSA $(<2.5 \mathrm{ng} / \mathrm{mL})$, f/tPSA ratio $(0.15)$ and PSA Density $(0.15 \mathrm{ng} / \mathrm{mL} / \mathrm{cc})$ cut off values, which are used in the diagnosis of prostate cancer and defined in guidelines, can be used routinely [18] [19] [20].

PV, tPSA, fPSA and PSA-D can be used to differentiate ASAP from prostate cancer tissue (p: 0.01, p: 0.001, p: 0.02, p: 0.001, respectively). PV and f/tPSA ratio can be predictive for positive repeat biopsy [21]. PV, tPSA and PSA Density were significantly different between group 2 and group 3.

A study in France; Full blood count (FBC) normal reference values for adults were defined and WBC count, NC, LC, NLR, MPV, PLT count and PLR levels were found $6.6 \times 10^{3} / \mathrm{mm}^{3}, 3.6 \times 10^{3} / \mathrm{mm}^{3}, 2.3 \times 10^{3} / \mathrm{mm}^{3}, 1.56,8.7 \mathrm{fL}, 269 \times$ $10^{3} / \mathrm{mm}^{3}$ and 116.95 , respectively [22]. Compared with this study, WBC levels were higher in all groups. Similarly NC levels were higher in all groups, but NC lowest levels were observed in group $1\left(4.53 \pm 1.23 \times 10^{3} / \mathrm{mm}^{3}\right)$. LC levels in groups 2 and 3 were lower than normal $\left(2.26 \pm 1.09\right.$ and $2.26 \pm 0.69 \times 10^{3} / \mathrm{mm}^{3}$, respectively). NLR levels were higher in all groups and group 2 higher than others. There was statistically significant difference between group 1 and 2 (p: 0.03). MPV levels were lower in all groups and the lowest in group 3. There was statistically significant difference between group 2 and 3 (p: 0.04). PLT and PLR levels were lower in all groups. There was statistically significant difference in PLR levels between group 1 and 2 (p: 0.02). 
The likelihood of ASAP detection in prostate biopsy result increased when the blood levels rise of NLR and PLR. This result supports the inflammatory processes in the formation of ASAP [23] [24]. The normal range of NLR and PLR vary by age. Mean values at $40-49,50-59,60-69$ and $>70$ years are 1.75, 1.48, 1.49 and 1.61 for NLR and 151.78, 136.22, 128.94 and 121.42 for PLR, respectively [25]. The mean NLR values of patients in our study consistent with literature. Our NLR levels in ASAP were found higher than the results of this study (2.85 \pm 2.64), but PLR levels were similar (125.88 \pm 65.64$)$.

Mean platelet volume (MPV) is commonly used indicator of platelet activation. The range of MPV in Turkish healthy subjects is $8.9 \pm 1.4 \mathrm{fL}$ [26]. When the literature is evaluated, it is seen that MPV levels were estimated in genitourinary cancers such as prostate, renal or testicular cancers. Gokcen, et al. [27] et al. found that MPV was significantly lower in testicular cancer group compared to the healthy group. MPV, NLR and PLR may be helpful for prediagnosis of testicular cancers. In another similar study in patients with renal cell carcinoma, MPV was significantly lower in renal cell carcinoma group compared to the control group [28]. In recent years MPV has been used to differentiate PCa from benign prostate tissue. Fu, et al. [29] et al. found that reduced MPV and elevated PSA in patients with PCa have had and the combination of PSA, MPV, and PDW may be clinically useful in distinguishing between $\mathrm{PCa}$ and benign prostate tissue. In contrast to genitourinary cancers, MPV values may increase in cases with nonsymptomatic prostatitis [30]. Another study supporting this result, MPV values significantly decreased after treatment in prostatitis. This supports MPV as an inflammation marker [31]. In our study, MPV values were lower than healthy subjects. The lowest value was found in the prostate cancer group $(7.74 \pm 1.15 \mathrm{fL})$. The highest value was detected in the ASAP group which is closely related to inflammation $(8.29 \pm 1.37 \mathrm{fL})$.

The limitations of the study; evaluation of data retrospectively, not contain large patient cohorts and the absence of an effective parameter or threshold in differentiation of benign and malignant prostate tissue. More studies are needed about complete blood count parameters to predict of biopsy results.

\section{Conclusion}

Nowadays, prostate biopsy is used in the differential diagnosis of many factors that cause PSA elevation. However, it is not easy to perform because prostate biopsy is an invasive procedure in patients. Therefore, besides the PSA value, the diagnostic value of additional analyzes is needed. The high values of NLR, PLR and MPV play an effective role in the prediction of ASAP, but the low MPV value supports the possibility of prostate cancer. Considering these results, we recommend that the complete blood count parameters should be examined carefully before prostate biopsy and the possible diagnoses are evaluated in this context.

\section{Conflicts of Interest}

The authors certify that there is no conflict of interest with any financial organi- 
zation regarding the material discussed in the manuscript.

\section{References}

[1] Caglayan, V., Onen, E., Avci, S., Sambel, M., Kilic, M., Oner, S., Aydos, M.M. and Yildiz, H.E. (2019) Lymphocyte-to-Monocyte Ratio Is a Valuable Marker to Predict Prostate Cancer in Patients with Prostate Specific Antigen between 4 and 10 ng/dl. Archives of Italian Urology and Andrology, 90, 270-275.

https://doi.org/10.4081/aiua.2018.4.270

[2] Kaynar, M., Yildirim, M.E., Gul, M., Kilic, O., Ceylan, K. and Goktas, S. (2015) Benign Prostatic Hyperplasia and Prostate Cancer Differentiation via Platelet to Lymphocyte Ratio. Cancer Biomarkers, 15, 317-323. https://doi.org/10.3233/CBM-150458

[3] Arda, E., Yuksel, I., Cakiroglu, B., Akdeniz, E. and Cilesiz, N. (2018) Valuation of Neutrophil/Lymphocyte Ratio in Renal Cell Carcinoma Grading and Progression. Cureus, 10, e2051. https://doi.org/10.7759/cureus.2051

[4] Epstein, J.I., Allsbrook Jr., W.C., Amin, M.B., Egevad, L.L. and Committee, I.G. (2005) The 2005 International Society of Urological Pathology (ISUP) Consensus Conference on Gleason Grading of Prostatic Carcinoma. The American Journal of Surgical Pathology, 29, 1228-1242.

https://doi.org/10.1097/01.pas.0000173646.99337.b1

[5] Egevad, L., Delahunt, B., Srigley, J.R. and Samaratunga, H. (2016) International Society of Urological Pathology (ISUP) Grading of Prostate Cancer: An ISUP Consensus on Contemporary Grading. APMIS, 124, 433-435. https://doi.org/10.1111/apm.12533

[6] Siegel, R.L., Miller, K.D. and Jemal, A. (2018) Cancer Statistics, 2018. CA: A Cancer Journal for Clinicians, 68, 7-30. https://doi.org/10.3322/caac.21442

[7] Shariat, S.F. and Roehrborn, C.G. (2008) Using Biopsy to Detect Prostate Cancer. Reviews in Urology, 10, 262-280.

[8] Amiel, G.E. and Slawin, K.M. (2006) Newer Modalities of Ultrasound Imaging and Treatment of the Prostate. Urologic Clinics of North America, 33, 329-337. https://doi.org/10.1016/j.ucl.2006.04.003

[9] Pallwein, L., Mitterberger, M., Gradl, J., Aigner, F., Horninger, W., Strasser, H., Bartsch, G., zur Nedden, D. and Frauscher, F. (2007) Value of Contrast-Enhanced Ultrasound and Elastography in Imaging of Prostate Cancer. Current Opinion in Urology, 17, 39-47. https://doi.org/10.1097/MOU.0b013e328011b85c

[10] Gann, P.H. (2002) Risk Factors for Prostate Cancer. Reviews in Urology, 4, S3-S10.

[11] Iczkowski, K.A., Bassler, T.J., Schwob, V.S., Bassler, I.C., Kunnel, B.S., Orozco, R.E. and Bostwick, D.G. (1998) Diagnosis of "Suspicious for Malignancy" in Prostate Biopsies: Predictive Value for Cancer. Urology, 51, 749-758. https://doi.org/10.1016/S0090-4295(98)00109-5

[12] Ouyang, R.C., Kenwright, D.N., Nacey, J.N. and Delahunt, B. (2001) The Presence of Atypical Small Acinar Proliferation in Prostate Needle Biopsy Is Predictive of Carcinoma on Subsequent Biopsy. BJU International, 87, 70-74.

https://doi.org/10.1046/j.1464-410x.2001.00989.x

[13] Scattoni, V., Roscigno, M., Freschi, M., Briganti, A., Fantini, G.V., Bertini, R., Salonia, A., Montorsi, F. and Rigatti, P. (2005) Predictors of Prostate Cancer after Initial Diagnosis of Atypical Small Acinar Proliferation at 10 to 12 Core Biopsies. Urology, 66, 1043-1047. https://doi.org/10.1016/j.urology.2005.05.006 
[14] Ryu, J.H., Kim, Y.B., Lee, J.K., Kim, Y.J. and Jung, T.Y. (2010) Predictive Factors of Prostate Cancer at Repeat Biopsy in Patients with an Initial Diagnosis of Atypical Small Acinar Proliferation of the Prostate. Korean Journal of Urology, 51, 752-756. https://doi.org/10.4111/kju.2010.51.11.752

[15] Verma, A., St Onge, J., Dhillon, K. and Chorneyko, A. (2014) PSA Density Improves Prediction of Prostate Cancer. Canadian Journal of Urology, 21, 7312-7321.

[16] Pezaro, C., Woo, H.H. and Davis, I.D. (2014) Prostate Cancer: Measuring PSA. Internal Medicine Journal, 44, 433-440. https://doi.org/10.1111/imj.12407

[17] Liu, M., Hou, H.M., Li, X., Zhang, Y.Q., Wan, B., Wang, J.Y. and Jin, B. (2016) Value of Prostate Volume, PSAD and F/T in the Detection of Prostate Cancer in Males with PSA 4-10 mug/L. Chinese Journal of Oncology, 38, 526-529.

[18] Catalona, W.J., Smith, D.S. and Ornstein, D.K. (1997) Prostate Cancer Detection in Men with Serum PSA Concentrations of 2.6 to $4.0 \mathrm{ng} / \mathrm{mL}$ and Benign Prostate Examination. Enhancement of Specificity with Free PSA Measurements. JAMA, 277, 1452-1455. https://doi.org/10.1001/jama.1997.03540420048028

[19] Seaman, E.K., Whang, I.S., Cooner, W., Olsson, C.A. and Benson, M.C. (1994) Predictive Value of Prostate-Specific Antigen Density for the Presence of Micrometastatic Carcinoma of the Prostate. Urology, 43, 645-648.

https://doi.org/10.1016/0090-4295(94)90179-1

[20] Brawer, M.K., Aramburu, E.A., Chen, G.L., Preston, S.D. and Ellis, W.J. (1993) The Inability of Prostate Specific Antigen Index to Enhance the Predictive the Value of Prostate Specific Antigen in the Diagnosis of Prostatic Carcinoma. Journal of Urology, 150, 369-373. https://doi.org/10.1016/S0022-5347(17)35485-X

[21] Mearini, L., Costantini, E., Bellezza, G., Cavaliere, A., Zucchi, A., Bini, V. and Porena, M. (2008) Is There Any Clinical Parameter Able to Predict Prostate Cancer after Initial Diagnosis of Atypical Small Acinar Proliferation? Urologia Internationalis, 81, 29-35. https://doi.org/10.1159/000137637

[22] Troussard, X., Vol, S., Cornet, E., Bardet, V., Couaillac, J.P., Fossat, C., Luce, J.C., Maldonado, E., Siguret, V., Tichet, J., Lantieri, O. and Corberand, J. (2014) French-Speaking Cellular Hematology G: Full Blood Count Normal Reference Values for Adults in France. Journal of Clinical Pathology, 67, 341-344. https://doi.org/10.1136/jclinpath-2013-201687

[23] Mimeault, M. and Batra, S.K. (2013) Development of Animal Models Underlining Mechanistic Connections between Prostate Inflammation and Cancer. World Journal of Clinical Oncology, 4, 4-13. https://doi.org/10.5306/wjco.v4.i1.4

[24] Kusumanto, Y.H., Dam, W.A., Hospers, G.A., Meijer, C. and Mulder, N.H. (2003) Platelets and Granulocytes, in Particular the Neutrophils, form Important Compartments for Circulating Vascular Endothelial Growth Factor. Angiogenesis, 6, 283-287. https://doi.org/10.1023/B:AGEN.0000029415.62384.ba

[25] Lee, J.S., Kim, N.Y., Na, S.H., Youn, Y.H. and Shin, C.S. (2018) Reference Values of Neutrophil-Lymphocyte Ratio, Lymphocyte-Monocyte Ratio, Platelet-Lymphocyte Ratio, and Mean Platelet Volume in Healthy Adults in South Korea. Medicine (Baltimore), 97, e11138. https://doi.org/10.1097/MD.0000000000011138

[26] Demirin, H., Ozhan, H., Ucgun, T., Celer, A., Bulur, S., Cil, H., Gunes, C. and Yildirim, H.A. (2011) Normal Range of Mean Platelet Volume in Healthy Subjects: Insight from a Large Epidemiologic Study. Thrombosis Research, 128, 358-360. https://doi.org/10.1016/j.thromres.2011.05.007

[27] Gokcen, K., Dundar, G., Gulbahar, H., Gokce, G. and Gultekin, E.Y. (2018) Can Routine Peripheral Blood Counts like Neutrophil-to-Lymphocyte Ratio Be Benefi- 
cial in Prediagnosis of Testicular Cancer and Its Stages? Journal of Research in Medical Sciences, 23, 64. https://doi.org/10.4103/jrms.JRMS_1009_16

[28] Yun, Z.Y., Zhang, X., Liu, Z.P., Liu, T., Wang, R.T. and Chen, H. (2017) Association of Decreased Mean Platelet Volume with Renal Cell Carcinoma. International Journal of Clinical Oncology, 22, 1076-1080.

https://doi.org/10.1007/s10147-017-1158-2

[29] Fu, S., Zhang, X., Niu, Y. and Wang, R.T. (2018) Prostate Specific Antigen, Mean Platelet Volume, and Platelet Distribution Width in Combination to Discriminate Prostate Cancer from Benign Prostate Hyperplasia. Asian Pacific Journal of Cancer Prevention, 19, 699-702.

[30] Rifaioglu, M.M., Demirbas, O., Gokce, H. and Davarci, M. (2017) Mean Platelet Volume-A Predictive Factor for the Diagnosis of Nonsymptomatic Prostatitis: Results of Univariate and Multivariate Models. American Journal of Men's Health, 11, 35-40. https://doi.org/10.1177/1557988315621144

[31] Karaman, H., Karakukcu, C. and Kocer, D. (2013) Can Mean Platelet Volume Serve as a Marker for Prostatitis? International Journal of Medical Sciences, 10, 1387-1391.

https://doi.org/10.7150/ijms.6126 